\title{
Ciencia Transparente para Todos
}

\section{Open Science for All}

\author{
Eugenio Matijasevic • Bogotá, D.C. (Colombia)
}

En ciencias de la computación se denomina con el anglicismo software al conjunto de instrucciones lógicas (procesos, algoritmos, programas) que hacen posible que una máquina de procesamiento informático o computadora realice una determinada tarea. No sólo en castellano es nuevo este término, también en inglés data aproximadamente de la década de1950. Surgió como un derivado de hardware, un término mucho más antiguo. En inglés ware se usa como un sustantivo genérico para designar productos manufacturados, artefactos en los que ha intervenido de una manera u otra la mano del hombre. Pero más que como sustantivo independiente, ware se utiliza como sufijo en la formación de múltiples palabras (por ejemplo en tinware para referirse a cualquier utensilio hecho de hojalata o earthenware para todos los cacharros de cocina hechos de barro cocido o stoneware para los de cerámica). Hardware se refería, por lo menos desde 1515, a todas las partes de una nave o de una máquina manufacturadas con base en metales (1). A partir de 1947 comenzó a usarse para referirse, además, a los componentes físicos (mecánicos, magnéticos, electrónicos, etc.) de una computadora (2). La creación de la nueva palabra, desmembrando hardware (literalmente: artefacto duro) para transformarla en soft-ware [literalmente: artefacto blando), habla muy bien del genio popular del idioma supliendo de manera ingeniosa las necesidades comunicativas a medida que los desarrollos tecnológicos nos obligan a crear nuevos términos (Paul Niquette pretende haber acuñado el término en 1953, pero sólo contamos con su testimonio (3); la primera referencia escrita a software data de 1956 pero no es muy claro que se esté utilizando en el sentido que nos interesa (4); la primera aparición escrita en la que software aparece opuesto a hardware data de 1958 (5) y se debe a John Turkey, quien también acuñó la palabra bit e inventó el diagrama de caja que tanto usamos en la representación gráfica de datos estadísticos que incluyan mínima, máxima, mediana y primero y tercer cuartil (6)].

Hardware y software son términos que han pasado a todas las lenguas prácticamente sin cambios. Se ha pretendido traducirlos al castellano de muy diversas maneras (por ejemplo, equipo informático, equipo físico o computadora para el primero y programa lógico, sistema y aplicaciones para el segundo), pero en realidad ninguno de estos términos abarca de manera precisa el significado que tienen los términos originales.

Es ya un lugar común referirse a los libros como herramientas. En una bella metáfora Borges asimiló los libros a las herramientas, ya no como extensiones del brazo o del cuerpo, sino como extensiones de la memoria y de la imaginación (7). Aunque Borges pudo apenas vislumbrar el comienzo de la era informática, seguramente estaría de acuerdo en incluir dentro de su metáfora no sólo todos los dispositivos electrónicos disponibles para fijar un texto, guardarlo y poder leerlo después (es decir, los libros electrónicos) sino también, ¿por qué no?, las computadoras. Sin embargo hay una diferencia que no permite que la metáfora sea perfecta.

Una herramienta común y corriente, pongamos por caso un serrucho o un martillo, es un artefacto que utilizamos como extensión de nuestro cuerpo con miras a realizar un cierto trabajo. Cualquier herramienta dentro de esta categoría, serrucho o martillo, cumple sus funciones en las manos de un usuario autónomo que, después de un cierto tiempo de entrenamiento con un experto (en raras ocasiones a partir de la propia práctica, por ensayo y error), aprende a utilizar la herramienta y conoce un conjunto de instrucciones que están en su propia mente y posee unas ciertas habilidades que están en su propio cuerpo.
Dr. Eugenio Matijasevic: Editor General, Acta Médica Colombiana. Bogotá, D.C. (Colombia)

E-mail: eugenio.matijasevic@gmail.com Recibido: 27/IX/2012 Aceptado: 28/IX/2012 
Un libro es una extensión de nuestra memoria y de nuestra imaginación destinado a guardar un cierto contenido (un texto escrito, imágenes o ambas). Su adecuada interacción con el usuario requiere un proceso más largo que el de las herramientas comunes y corrientes, pues se trata de una herramienta más compleja: el usuario debe primero aprender, de manos de un experto, el lenguaje y la lectura al tiempo que aprende a utilizar el libro para auxiliar su memoria y su imaginación (a no ser que prefiera limitarse a ayudar a su memoria viendo imágenes en el libro, en cuyo caso no necesita aprender a leer). Pero de todas maneras es el usuario quien tiene en su cabeza las instrucciones necesarias (saber leer, sostener el libro en la posición correcta, pasar las páginas) para el adecuado uso de esta herramienta.

El procesador informático o computadora es una herramienta aún más compleja que el libro: su interacción con el usuario, en primer lugar, requiere una interfaz hombremáquina (pantallas táctiles, teclados, ratones, trackpads) que permita, casi siempre mediante comandos codificados de manera gráfica, darle a la máquina las instrucciones necesarias para que realice la tarea que queremos. Pero, si bien el usuario sólo tiene que aprender unas cuantas reglas básicas sobre el manejo de la interfaz (y con la ayuda de un experto o por ensayo y error, pronto será un experto a su vez), la computadora no puede hacer ninguna tarea si no posee, además, un código preestablecido de instrucciones en el que a cada instrucción está asociada a una tarea específica. Resumiendo: para que la computadora realice las tareas que queremos que realice esta herramienta, es indispensable que, además de las instrucciones que debemos tener en nuestra mente para el manejo de la interfaz, exista un conjunto de instrucciones en la computadora que establezcan qué tarea debe realizar cada vez que nosotros modificamos de alguna manera el estado de cosas en la interfaz. El usuario interactúa con la interfaz, esta con la aplicación, la aplicación con el sistema operativo y este con el hardware (y todo lo que no es hardware es software: interfaz, aplicaciones, sistema operativo). Se trata de algo inédito en la historia de las herramientas: para que la computadora funcione se requiere que, integrado al hardware de la misma, exista un software en el que sea posible indicar qué funciones realizar. Sin software y hardware a la vez no hay herramienta, no hay computadora. Se trata de una herramienta de nuevo cuño, ni el serrucho, ni el martillo, ni el libro tienen que incluir, como parte de su esencia, instrucciones para sí mismos de tal manera que la herramienta pueda desplegar sus capacidades y ponerlas al servicio del usuario, la computadora sí: si no fuese por el conjunto de instrucciones que incluye como software, la computadora no podría ayudarnos en su tarea como extensión de la memoria.

Ahora bien, yo puedo afirmar que soy el propietario de este martillo o de aquel serrucho, pero en ninguno de los dos casos puedo afirmar que poseo también derechos de usufructo inalienables sobre las instrucciones para utilizar el martillo o el serrucho o que sólo yo puedo utilizar determi- nado estilo de martilleo. Si yo fuese por ahí diciendo que, de ahora en adelante, nadie puede martillar así o asá sin obtener previamente un permiso o certificado mío (y que además debe pagar por obtenerlo) la carcajada sería universal.

Con los libros ocurre al contrario. Yo puedo afirmar que soy el dueño de este libro, llevarlo conmigo, prestarlo, regalarlo, pero no se me permite volverlo a imprimir o modificar su contenido a no ser que yo pueda afirmar que soy el autor del libro y que voy a hacer una nueva edición. Si intentase publicar "El Ingenioso Hidalgo Don Quijote de la Mancha" modificando un par de capítulos que no me gustan o si estableciese una oficina destinada a conceder permisos para que otros lo publiquen con sus propias modificaciones, aunque Don Miguel de Cervantes ya no puede defender su obra, la comunidad académica cervantina se encargaría de hacer público el engaño.

Con las instrucciones de la computadora ocurre algo parecido que con los libros: quienes desarrollan y ponen a punto dichas instrucciones pretenden que no sean utilizadas por todo el mundo sin pagar una cierta cantidad de dinero (licencia) que supuestamente compense su trabajo. Cada vez que compro una computadora, de la marca que sea, debo comprar la licencia que me permita utilizar el software. Si no pago por la licencia infringiré las normas sobre derechos de autor al utilizar el software. Pero al comprar la licencia sólo estoy pagando por el derecho a usar ese software, no lo he comprado, no soy su propietario, ese software es "cerrado": tengo derecho a correr en mi computadora ese conjunto de instrucciones (ejecutar los programas) pero, al igual que con los libros, no puedo copiarlo para distribuirlo ente otros usuarios y, sobre todo, no tengo derecho a abrir su código para estudiar sus reglas y algoritmos y, mucho menos, como en el caso de "El Quijote", puedo cambiarlos.

Existe, sin embargo, software libre: instrucciones para el funcionamiento de las computadoras que no sólo puedo correr en mi computadora sino también abrir su código, estudiar sus reglas y algoritmos e incluso cambiarlos. Los cuatro tipos de libertades para los usuarios de software son, de acuerdo con la Free Software Foundation (FSF):

Libertad 0: libertad de usar el programa con cualquier propósito.

Libertad 1: libertad de estudiar el funcionamiento del programa y adaptarlo a las necesidades del usuario (el acceso al código fuente es en este caso un prerrequisito indispensable).

Libertad 2: libertad de distribuir copias del programa para ayudar a los demás.

Libertad 3: libertad de mejorar el programa y de publicar las mejoras, de modo que toda la comunidad se beneficie (el acceso al código fuente es también en este caso un prerrequisito indispensable) (8).

Cualquier software que cumpla con las cuatro libertades mencionadas puede ser certificado como free software, por una entidad especializada perteneciente al movimiento de 
free software (por ejemplo la FSF otorga la GNU General Public License). En castellano no tenemos el inconveniente que se da entre los angloparlantes, que para expresar los conceptos de "gratis" y "libre" sólo tienen un término, de tal manera que cuando en inglés se dice free software alguien puede creer que se trata de programas gratuitos de computadora. En febrero de 1998 otro grupo de apoyo a la libertad informática (el Debian Project) propuso reemplazar el término free software (software libre, pero también, equívocamente, software gratis) por open software (software abierto) o también open source software (software de código abierto), con el fin de evitar malentendidos (especialmente para que la industria de la informática no asociara la idea de acceso abierto a los códigos con la de gratuidad). El software de código abierto no necesariamente es gratuito, pero puesto que cualquiera con la capacidad suficiente para modificar los algoritmos e instrucciones de los programas podrá modificarlos (y será la comunidad de usuarios la que decida si los cambios aportados constituyen o no una ventaja), las leyes del mercado mantendrán siempre los mejores productos a los menores precios.

En realidad, ambos términos, software libre y software abierto, se refieren esencialmente a lo mismo. Las directrices de código abierto fueron creadas a partir de las directrices de software libre de Debian y no hay ningún problema al tratar de traducir éstas a las directrices de la FSF, aunque la FSF prefiere el término software libre porque "una vez que queda claro que se refiere a la libertad y no al precio, evoca la idea de libertad, mientras que la palabra abierto nunca se refiere a la libertad" (9).

Como todo movimiento enmarcado en el contexto de la era informática, la posibilidad de difundir de manera inusitada estos conceptos ha llevado a que usuarios, instituciones educativas, institutos independientes, fundaciones sin ánimo de lucro, organizaciones no gubernamentales e incluso instituciones gubernamentales, hayan apoyado de forma masiva las iniciativas encaminadas a un software libre o abierto. En la actualidad es posible encontrar a través de la internet desde sistemas operativos abiertos [como GNU/ Linux (10)] hasta aplicaciones abiertas con procesador de palabras, hoja de cálculo, presentación de diapositivas, hoja de dibujo y base de datos [como Apache OpenOffice (11)].

La iniciativa por la apertura de la información ha comenzado a permear ámbitos antaño completamente cerrados, como la publicación de libros. Existen compañías editoriales "abiertas" como Open Book Publishers, en donde se pueden conseguir gratuitamente libros en formato electrónico para su lectura directamente en la Internet o para comprarlos en formato físico por precios realmente bajos (12). Existen bases de datos en la Internet destinadas a almacenar, leer y evaluar publicaciones científicas en su etapa de preprensa (repositorios es el nombre que se les ha dado en castellano). Los trabajos científicos allí almacenados no se pueden citar porque oficialmente aún no han sido publicados: están allí únicamente para ser evaluados por pares tal como ocurre con los trabajos científicos enviados para posible publicación a una revista arbitrada e indexada como Acta Médica Colombiana, pero en el caso de estos repositorios no se trata de evaluación por unos cuantos pares ciegos (puesto que el autor o autores del trabajo no saben quienes son los pares y los pares, a su vez, no conocen quienes son los autores), sino de la evaluación abierta y transparente de toda la comunidad científica, de todo aquel que se sienta con derecho y capacidad para opinar de manera científica sobre el trabajo que se expone allí al análisis público antes de ser aceptado por la comunidad científica como un trabajo científico que, por tanto, puede ser publicado. Una vez sometido al escrutinio público por parte de la comunidad científica, el autor o autores eligen a qué revista enviarlo para su publicación luego de haberse enriquecido con los comentarios de múltiples evaluadores. El repositorio más conocido es en la actualidad arXiv (13), desarrollado originalmente por Paul Ginsparg en 1991, pero sólo acepta trabajos de física, astronomía, matemáticas, ciencias de la computación, ciencia no lineal, biología cuantitativa y estadística.

Otros grupos han seguido una ruta intermedia y han creado verdaderas publicaciones científicas periódicas arbitradas por pares con una característica especial que han denominado open access (de acceso abierto) a través de la Internet. Para estas publicaciones acceso abierto significa que todo el mundo puede acceder al trabajo publicado en la revista sin necesidad de subscripción ni pago alguno y que pueden leerlo, descargarlo y redistribuirlo sin costo adicional, de tal manera que la investigación tenga el máximo impacto posible. Un ejemplo de este método de publicación científica periódica en línea es el grupo de revistas Public Library of Science (PLOS) que incluye las publicaciones periódicas PLOS ONE, PLOS Biology, PLOS Medicine, PLOS Genetics, PLOS Computational Biology, PLOS Pathogens y PLOS Neglected Tropical Diseases (14).

Pero mientras arXiv garantiza el cubrimiento de sus costos de funcionamiento a través de donaciones de diversas entidades y de grants gubernamentales, PLOS cobra una tarifa al autor o al patrocinador de cada investigación publicada con el fin de cubrir los gastos de evaluación por pares, producción de la revista, hospedaje (hosting) y archivo en la Internet. La tarifa para publicar un artículo una vez ha sido aceptado para publicación después de la evaluación por pares puede ir desde US $\$ 2900$ si la investigación proviene de uno de los países del primer mundo, hasta US\$500 si proviene de países apenas en vías de desarrollo (Colombia está incluida en esta lista) o incluso nada si la investigación proviene de países subdesarrolados (15).

Para iniciativas como la de arXiv, PLOS y otras similares que pululan en la Internet, se ha acuñado el término genérico Open Science (ciencia abierta), un movimiento que quiere que la investigación científica sea accesible a la sociedad en todos sus niveles y no un monopolio de unos cuantos. El movimiento de Ciencia Abierta propende no sólo por el acceso abierto (open access) a la investigación científica sino que ha 
querido ir también más lejos, convocando a los científicos a que practiquen ciencia de cuaderno de notas abierto (open notebook science) de tal manera que todo el material original del proyecto de investigación esté públicamente disponible en línea a medida que se van recopilando los datos, para que la investigación pueda ser seguida, escrutada y acompañada a lo largo de todo el proceso (16).

Algunos científicos lo han hecho pero, en general, a los científicos no les gusta nada que los demás (sobre todo sus colegas) anden fisgoneando en sus asuntos. Temen que les roben sus secretos, que un grupo competidor encuentre en sus experimentos la clave que le hacía falta para sacarle ventaja y llegar antes a conclusiones que pueden generar patentes y dinero. Quienes los financian temen los mismo, y por la misma razón les gusta aún menos que otros anden fisgoneando en los asuntos de los científicos de los que depende su éxito financiero. Se trata de un verdadero conflicto de intereses pero de carácter neurótico irresoluble porque no basta con aceptarlo y declararlo: el conflicto siempre estará ahí, si algo desearía un científico sería disponer de todos los recursos y de toda la información indispensables para sacar adelante y cuando antes su investigación, le encantaría saber en qué andan sus pares, los investigadores que están investigando en su mismo campo o en campos afines, qué saben que él no sepa que podría ayudarlo a desatascar su investigación; en síntesis, llevando la situación al extremo, le gustaría saber todo lo que saben y hacen los demás pero sin reciprocidad, no le gustaría que lo que él sabe y hace también lo sepan y lo puedan hacer los demás. Ese egoísmo infantil es connatural a nuestra especie, pero también es connatural el empleo de la razón y de modelos de pensamiento más realista que nos ayudan a entender que sin colaboración no es posible el desarrollo científico, que como individuos no podemos saberlo todo y que necesitamos de otros para, a partir de los pequeños saberes de todos, construir el inmenso edificio que en la actualidad podemos llamar ciencia.

La idea de que la ciencia debe ser abierta, transparente, ha llegado también a los procesos de edición de publicaciones científicas periódicas. En 1998, John Willinsky, del Departamento de Literatura y Lenguas de la Facultad de Educación de la Universidad de California en Berkeley, comenzó a desarrollar, a partir de sus conocimientos sobre historia de las publicaciones y de su experiencia en el desarrollo de software educativo en Knowledge Architecture Inc., un programa que denominó Public Knowledge Project (PKP: Proyecto para el Conocimiento Público) (17). En la actualidad el PKP es patrocinado por la Universidad de Stanford, la Biblioteca de la Universidad Simon Fraser, el Canadian Centre for Studies in Publishing de la misma Universidad Simon Fraser y la Facultad de Educación de la Universidad de California en Berkeley.

El primer software desarrollado por PKP, con la ayuda técnica de Kevin Jamieson, fue Open Journal Systems (OJS: Sistemas para Revistas Abiertas), un software dedicado a la edición de publicaciones científicas periódicas arbitradas por pares que permite la recepción de los artículos a través de la Internet, la evaluación de los mismos por parte del Comité Editorial, la asignación ciega de cada trabajo de investigación a pares académicos, la evaluación ciega por parte de los pares y la devolución a la revista con la consiguiente calificación del trabajo e incluso gran parte del trabajo de edición de la revista (creación de números de la revista, asignación de trabajos a las distintas secciones, revisión de las galeradas por los autores para su aprobación final antes de la impresión, etc.) (18). Durante todo el proceso los editores, autores, y revisores pueden seguir en detalle en qué parte del proceso va un determinado trabajo, aunque sólo pueden intervenir en el aspecto que les corresponda en el proceso (un editor no puede intervenir como par, un par no puede modificar un trabajo, sólo hacer sugerencias, un autor no puede manipular las decisiones de los pares porque ni siquiera los conoce). Obviamente OJS, siendo un software para la creación y edición de revistas abiertas, es también un software abierto: todo aquel con el conocimiento y el tiempo para hacerlo puede modificarlo para mejorarlo (la comunidad de usuarios será la encargada de establecer si la modificación es buena y se mantiene). PKP ha desarrollado también software abierto para el desarrollo de conferencias científicas (Open Conference Systems, con la posibilidad de crear una página en la red para la conferencia, recibir a través de la misma los artículos, editarlos, publicar finalmente el texto con los artículos e incluso entablar discusiones en línea después de que la conferencia o el simposio o el congreso hayan terminado) (19), y para la creación, edición y publicación de monografías científicas, tesis de grado, etc. (Open Monograph Press) (20).

A partir de este número Acta Médica Colombiana inicia su transición hacia la edición con base en OJS. El cambio será gradual. Durante al menos uno o dos años, seguiremos recibiendo también trabajos de investigación en papel físico a través del correo aéreo y a través del correo electrónico, pero paulatinamente terminaremos por abandonar estos otros sistemas de recepción de trabajos para quedarnos exclusivamente en OJS.

Desde hace unos meses se encuentra disponible en http:// www.actamedicacolombiana.com, a manera de prueba, el enlace "enviar un artículo vía OJS". Algunos de ustedes ya lo han utilizado y queremos pedirles disculpas por haber tenido luego la necesidad de proseguir el trabado editorial vía correo electrónico, dado que el sistema no estaba aún completamente acoplado a todos los pasos de la edición de la revista, pero a partir de este número ya lo está y, aunque, como anuncié, seguiremos durante un tiempo recibiendo también trabajos por otras vías, esperamos que muy pronto todos los trabajos lleguen a Acta Médica Colombiana a través del nuevo sistema, como manifestación clara del compromiso de nuestra revista con la apertura y la transparencia de las publicaciones científicas. 


\section{Referencias}

1. Merriam-Webster Dictionary Premium. App for iPhone. Updated: Sep 04, 2012. Version: 2.0. Size: 23.0 MB. Language: English. Seller: Merriam-Webster, Inc.

2. Online Etymology Dictionary [Internet]. Disponible en: Hardware http://www. etymonline.com/index.php?term=hardware. Consultado el 1 de septiembre de 2012.

3. De Niquette P. Softword: Provenance for the Word 'Software' [Internet]. 2006. Disponible en http://niquette.com/books/softword/part0.htm. Consultado el 1 de septiembre de 2012.

4. American Society for Quality Control. Proceedings, second National Symposium on Quality Control and Reliability in Electronics. Sponsored by the Professional Group on Quality Control, Institute of Radio Engineers and the Electronics Technical Committee. Washington, D.C., January 9-10, 1956. Disponible en: http:/ catalog.hathitrust.org/Record/009752822. Consultado el 1 de septiembre de 2012.

5. Shapiro FR. The Yale Book of Quotations. New Haven: Yale University Press; 2006: p 772.

6. Brillinger DL. John W. Tukey: his life and professional contributions. The Annals of Statistics 2002; 30 (6): 1535-75.

7. Borges JL. Borges Oral. Madrid: Alianza Editorial; 2006: pp. 9-23.

8. Sistema Operativo GNU. La Definición de Software Libre [Internet]. Disponibe en: http://www.gnu.org/philosophy/free-sw.html. Consultado el 1 de septiembre de 2012.

9. Stallman R. Por qué el código abierto pierde el punto de vista del software libre [Internet]. Disponible en http://www.gnu.org/philosophy/open-source-misses-thepoint.html. Consultado el 2 de septiembre de 2012.
10. GNU/Linux [Internet]. Disponible en http://www.getgnulinux.org. COnsultado el 4 de septiembre de 2012.

11. Apache OpenOffice [Internet]. Disponible en http://www.openoffice.org/download/index.html. Consultado el 4 de septiembre de 2012.

12. Open Book Publishers [Internet]. Disponible en http://www.openbookpublishers com. Consultado el 5 de septiembre de 2012.

13. ArXiv [Internet]. Cornell University Library. Disponible en http://arxiv.org Consultado el 5 de septiembre de 2012.

14. Public Library of Science. PLOS [Internet]. Disponible en http://www.plos.org Consultado el 6 de septiembre de 2012.

15. PLOS. Publication Fees [Internet]. Disponible en http://www.plos.org/publish/ pricing-policy/publication-fees/. Consultado el 6 de septiembre de 2012.

16. O'Boyle NM, Guha R, Willighagen EL, et al. Open Data, Open Source and Open Standards in chemistry: The Blue Obelisk five years on. Journal of Cheminformatics 2011; 3 (1): 37-52.

17. Public Knowledge Project. History. Disponible en http://pkp.sfu.ca/history. Consultado el 7 de septiembre de 2012

18. Public Knowledge Project. Open Journal Systems [Internet]. Disponible en http:// pkp.sfu.ca/?q=ojs. Consultado el 10 de agosto de 2012.

19. Public Knowledge Project. Open Conference Systems [Internet]. Disponible en http://pkp.sfu.ca/?q=ocs. Consultado el 10 de agosto de 2012.

20. Public Knowledge Project. Open Monograph Press [Internet]. Disponible en http:// pkp.sfu.ca/omp. Consultado el 10 de agosto de 2012. 